\title{
The Quality of Chlorpyrifos Emulsifiable Concentrate Formulations
}

\author{
M. H. M. Ahmed, I. S. Ahmed, M. A. Saleh ${ }^{*}$ and I. I. Ismail \\ Chemistry Department, Faculty of Science, Benha University, \\ Benha, and ${ }^{*} P e s t i c i d e s$ Analysis Researches Department, \\ Central Agricultural Pesticides Laboratory, Agricultural \\ Research Center, Giza, Egypt.
}

\begin{abstract}
A STUDY was conducted to investigate the degradation of chlorpyrifos, as well as studying the formation of its impurity sulfotep after storage at $54 \pm 2{ }^{\circ} \mathrm{C}$ for $1,3,7,14,21$ days, at $72 \pm 2{ }^{\circ} \mathrm{C}$ for 1-5 days, and at room temperature within range 1-12 weeks of three commercial chlorpyrifos Emulsifiable Concentrate (EC) formulations $(48 \% \mathrm{w} / \mathrm{v})$ from the Egyptian market (manufactured from three different companies). The obtained results showed that chlorpyrifos was more stable after storage at $54 \pm 2{ }^{\circ} \mathrm{C}$ and at room temperature, whereas the rate of degradation increased after storage at $72 \pm 2{ }^{\circ} \mathrm{C}$. There is no difference on the rate of degradation for all chlorpyrifos formulations under investigation. The sulfotep content of the three commercial formulations didn't show any correlation with storage temperature and storage time. However, in one of the commercial formulations of chlorpyrifos, the sulfotep content was more than the maximum permissible concentration of impurity recommended by FAO Specifications for chlorpyrifos (2008).
\end{abstract}

Keywords: Chlorpyrifos, Degradation and Sulfotep.

Chlorpyrifos[O,O-diethyl-O-3,5,6-trichloro-2-pyridyl phosphorothioate] is an organophosphorus pesticide (OPP), which is a broadly active insecticide effective by ingestion and contact. The metabolites of chlorpyrifos being chlorpyrifos oxon, 3, 5, 6- trichloro -2- pyridinol and diethyl phosphorothioic acid and/or diethyl phosphoric acid ${ }^{(1,2)}$. Chlorpyrifos is stable in air (non volatile) and it is not sensitive to ultra violet radiation. It is stable to neutral and weakly acidic solution, but it is hydrolysed by strong bases. The rate of chlorpyrifos hydrolysis increases with both $\mathrm{pH}$ and temperature ${ }^{(3)}$. The effect of accelerated storage at $54 \pm 2{ }^{\circ} \mathrm{C}$ on chlorpyrifos and pirimiphos-methyl, indicated that the latter was more degraded than chlorpyrifos ${ }^{(4)}$. Technical chlorpyrifos can contain two interesting impurities and/ or breakdown products, sulfotep [ $O$, O, Ó,Ó-tetraethyl dithiopyrophosphate] and 3, 5,6 - trichloro pyridinol, the later is significant from a toxicological viewpoint ${ }^{(5)}$. According to FAO Specifications and Evaluations for chlorpyrifos (2008), sulfotep is the main impurity in chlorpyrifos (technical and formulations), it should not be higher 
than $3 \mathrm{~g} / \mathrm{kg}$ for technical chlorpyrifos, and $0.3 \%$ of chlorpyrifos content in all formulations of chlorpyrifos. Sulfotep is a highly toxic impurity that may be present in trace quantities in chlorpyrifos ${ }^{(6)}$. Since sulfotep has been shown formed during the manufacturing process ${ }^{(7)}$ and it is not hydrolysis product ${ }^{(8)}$.

The aim target of this work is to investigate and study the stability of three commercial chlorpyrifos emulsifiable concentrate formulations $(48 \% \mathrm{w} / \mathrm{v})$ from the Egyptian market (manufactured in three different companies), and the formation of its impurity sulfotep after storage at different intervals of temperature and time.

The structure and characterization of the investigated chlorpyrifos and their impurity sulfotep are shown in Fig. 1.

- Chlorpyrifos

IUPAC Name: O,O-diethyl-O-3,5,6-trichloro-2-pyridyl phosphorothioate.

Structural Formula:<smiles>CCO[Pb](=S)Oc1nc(Cl)c(Cl)cc1Cl</smiles>

Molecular Formula:

$\mathrm{C}_{9} \mathrm{H}_{11} \mathrm{Cl}_{3} \mathrm{NO}_{3}$ PS

Relative Molecular mass:

350.6

CAS Registry number:

2912-88-2

- Sulfotep as Impurity

IUPAC Name: O, O, Ó, Ó- Tetraethyl dithiopyrophosphate

Structural Formula:<smiles>CCOP(=S)(OCC)OP(=S)(OCC)OCC</smiles>

Molecular formula:

$\mathrm{C}_{8} \mathrm{H}_{20} \mathrm{O}_{5} \mathrm{P}_{2} \mathrm{~S}_{2}$

Relative Molecular mass:

322.32

CAS Registry number :

3689-24-5

Fig. 1.

Egypt. J. Chem. 53, No. 5 (2010) 
Materials

\section{Experimental}

Chlorpyrifos: analytical standard $99.4 \%$ from AAKO company Netherlands. Sulfotep analytical standard 97.1\%: from Chem. Service. Methanol: (MERCK). Isooctane: GR for analysis (MERCK).

Chlorpyrifos $48 \% \quad(\mathrm{w} / \mathrm{v})$ emulsifiable concentrate (EC) commercial formulation was obtained from three different Manufacture sources in Egypt (Manufactured in three different companies).

\section{Procedure}

Accelerated storage procedure ${ }^{(9)}$

Place the emulsifiable concentrate (about $50 \mathrm{ml}$ ) in the bottle. Cap the bottle and put it in the oven for specified time and temperature. At the end of the time, remove the bottle from the oven, remove the cap, and allow the bottle and contents to cool naturally to room temperature, replacing the cap when cool.

- Storage at $54 \pm 2{ }^{\circ} \mathrm{C}$ for $1,3,7,14,21$ days.

- Storage at $72 \pm 2{ }^{\circ} \mathrm{C}$ for $1,2,3,4,5$ days.

- Storage at room temperature for $1,2,4,6,8,10,12$ weeks.

\section{Preparation of samples}

Chlorpyrifos

Standard preparation: Weight $10 \mathrm{mg}$ of chlorpyrifos analytical standard inside a $25 \mathrm{ml}$ volumetric Flask then dissolve it and complete to the final volume with methanol.

Sample preparation: Accurately weight sufficient sample material formulation $48 \% \mathrm{w} / \mathrm{v}$ to equivalent $10 \mathrm{mg}$ of chlorpyrifos standard in a $25 \mathrm{ml}$ volumetric Flask mix slowly with methanol and complete the volume with methanol.

\section{Sulfotep}

Standard preparation: Weight $10 \mathrm{mg}$ of sulfotep analytical standard inside a $10 \mathrm{ml}$ volumetric Flask dissolve it with isooctane and complete the volume with isooctane.

Sample preparation: Accurately weight sufficient sample material formulation to contain approximately $0.3 \mathrm{gm}$ chlorpyrifos in $10 \mathrm{ml}$ volumetric flask, dissolve it with isooctane and complete the volume with isooctane.

\section{Measurements}

Gas chromatography determination for chlorpyrifos and sulfotep

A Hewlett-Packard 6890 gas chromatograph equipped with Flame Ionization Detector (FID) at $275^{\circ} \mathrm{C}$, capillary column HP-50\% (15 m x 0.53 $\mathrm{mm}$ I.D., $1 \mu \mathrm{m}$ film thickness). Nitrogen was used as a carrier gas at $20 \mathrm{ml} / \mathrm{min}$. 
The oven temperature program was held at $180{ }^{\circ} \mathrm{C}$ for $1 \mathrm{~min}$, then ramp $10^{\circ} \mathrm{C}$ $/$ min to $250^{\circ} \mathrm{C}$, and kept at that temperature for $5 \mathrm{~min}$. Injector temperature was $225{ }^{\circ} \mathrm{C}$. The injection volume was $1 \mu \mathrm{l}$. typical retention time of chlorpyrifos was $4.2 \mathrm{~min}$ and sulfotep was $1.9 \mathrm{~min}$.

\section{Gas chromatography-mass spectrometry analysis of chlorpyrifos}

The GC-MS analysis was performed with an Aglient 6890 gas chromatograph equipped with an Aglient mass spectrometric detector, with a direct capillary interface and fused silica capillary column HP-5MS(30 m x 320 $\mu \mathrm{m} \times 0.25 \mu \mathrm{m}$ film thickness). Helium was used as carrier gas at approximately $1.0 \mathrm{ml} / \mathrm{min}$ pulsed splitless mode. The solvent delay was $3 \mathrm{~min}$, and the injection volume was $1 \mu \mathrm{l}$. The mass spectrometric detector was operated in electron impact ionization mode with an ionizing energy of 70 e.v scanning from $\mathrm{m} / \mathrm{z} 50$ to 500 . The ion source temperature was $230{ }^{\circ} \mathrm{C}$ and the quadruple temperature $150{ }^{\circ} \mathrm{C}$. The electron multiplier voltage (EM voltage) was maintained $1050 \mathrm{v}$ above auto tune. The instrument was manually tuned using perfluorotributyl amine (PFTBA). The GC temperature program was held at 80 ${ }^{\circ} \mathrm{C}$ for $3 \mathrm{~min}$, then elevated to $260{ }^{\circ} \mathrm{C}$ at rate of $8{ }^{\circ} \mathrm{C} / \mathrm{min}$, the detector and injector temperatures were set at 280 and $250{ }^{\circ} \mathrm{C}$, respectively.

\section{Results and Discussion}

\section{Effect of storage stability on chlorpyrifos $48 \%$ EC content}

The data from Table 1, showed that the effect of storage at $54 \pm 2{ }^{\circ} \mathrm{C}$ on three commercial chlorpyrifos formulations indicated that, chlorpyrifos has not been changed by storage at $54 \pm 2{ }^{\circ} \mathrm{C}$ for 14,21 days, where the percentage of loss after 21 days was 3.85, 4.46 and $3.75 \%$ for sources I, II and III, respectively. However chlorpyrifos was more stable after storage at room temperature $25^{\circ} \mathrm{C}$ and Table 2 showed that the percentage of loss after 12 weeks was 2.12, 2.97 and $2.31 \%$ for sources I, II, and III, respectively, but Table 3 showed that the percentage of loss after storage at $72 \pm 2{ }^{\circ} \mathrm{C}$ for 5 days was $11.12,12.30$ and $12.35 \%$ for source I, II, and III, respectively. The stability of chlorpyrifos after storage at $72 \pm 2{ }^{\circ} \mathrm{C}$ for 5 days was less stable from storage at $25{ }^{\circ} \mathrm{C}$ and $54 \pm 2{ }^{\circ} \mathrm{C}$. The previously mentioned results cleary showed that the rate of degradation of the three chlorpyrifos formulations under investigation were influenced by change in temperature degrees and long period of storage. In general increasing temperature degrees increased the rate of degradation. The primary degradation product of chlorpyrifos can be explained by both hydrolysis and photolysis. The analysis of our samples by using GC-MS found that chlorpyrifos can be hydrolysed to 3, 5, 6- trichloro -2- pyridinol (TCP), also by electron impact found to give compounds 1,2 which in accordance with the hydrolysis. Phosphorus oxygen bond was cleaved to generate TCP and diethyl phosphorothioate, these results are in accordance with Smith ${ }^{(10)}$, this can be shown according to the following equation: 
<smiles>CCOP(=S)(OCC)Oc1nc(Cl)c(Cl)cc1Cl</smiles>

Chlorpyrifos

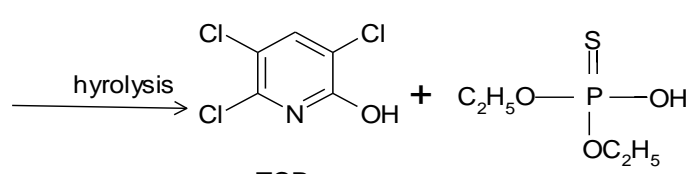

TCP

MS spectrum of chlorpyrifos as follows.

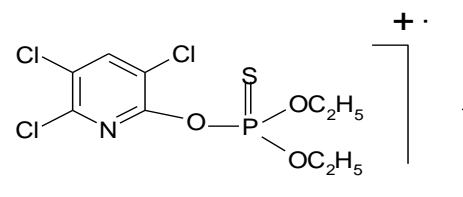

$\mathrm{m} / \mathrm{z}=353$<smiles></smiles>

(1)

$$
+\quad \begin{aligned}
& \mathrm{P} \\
& + \\
& \mathrm{P} / \mathrm{z}=153
\end{aligned}
$$

(2)

Mass fragmentation pattern of chlorpyrifos

Also, chlorpyrifos was converted to chlorpyrifos oxon by UV oxidation (11) as in the following equation:<smiles>CCOP(=S)(OCC)Oc1nc(Cl)c(Cl)cc1Cl</smiles>

Chlorpyrifos<smiles>COP(=O)(OC)Oc1nc(Cl)c(Cl)cc1Cl</smiles>

Chlorpyrifos Oxon

Organophosphates are normally stable at ambient temperature, but at elevated temperatures its isomers may be obtained. The $\mathrm{P}=\mathrm{S}$ (thiono) linkage may be isomerized to P-S- (thiolo) form and the product may be substantially more toxic to mammals ${ }^{(12)}$.

Form these results we observed that there is no difference on the rate of degradation for all chlorpyrifos formulations under investigation for storage at $54{ }^{\circ} \mathrm{C}, 72{ }^{\circ} \mathrm{C}$ and $25{ }^{\circ} \mathrm{C}$ (room temperature).

According to FAO specifications and evaluations (2008) for chlorpyrifos mentioned that the content of chlorpyrifos after storage at $54 \pm 2{ }^{\circ} \mathrm{C}$ for 14 days should not be lower than $95 \%$ relative to the content of chlorpyrifos before storage and this is achieved in this study according to Table 1. 
TABLE 1. Effect of storage stability on chlorpyrifos $48 \%$ w/v EC of three different manufacture sources at $54 \pm 2{ }^{\circ} \mathrm{C}$ for $1,3,7,14,21$ days.

\begin{tabular}{|c|c|c|c|c|c|c|}
\hline \multirow[b]{2}{*}{$\begin{array}{r}\text { Storage } \\
\text { periods } \\
\text { (Days) }\end{array}$} & \multicolumn{2}{|c|}{ Source I } & \multicolumn{2}{|c|}{ Source II } & \multicolumn{2}{|c|}{ Source III } \\
\hline & $\begin{array}{c}\text { Chlorpyrifos } \\
\text { content (w/v) } \\
\%\end{array}$ & $\begin{array}{c}\text { Loss } \\
\%\end{array}$ & $\begin{array}{c}\text { Chlorpyrifos } \\
\text { content (w/v) } \\
\%\end{array}$ & $\begin{array}{c}\text { Loss } \\
\%\end{array}$ & $\begin{array}{c}\text { Chlorpyrifos } \\
\text { content (w/v) } \\
\%\end{array}$ & $\begin{array}{c}\text { Loss } \\
\%\end{array}$ \\
\hline 0 & 47.02 & 0 & 47.09 & 0 & 47.2 & 0 \\
\hline 1 & 46.95 & 0.15 & 46.59 & 1.06 & 46.88 & 0.68 \\
\hline 3 & 46.85 & 0.36 & 46.42 & 1.42 & 46.6 & 1.27 \\
\hline 7 & 46.75 & 0.57 & 45.67 & 3.016 & 46.34 & 1.82 \\
\hline 14 & 46.1 & 1.96 & 45.38 & 3.63 & 45.81 & 2.94 \\
\hline 21 & 45.21 & 3.85 & 44.99 & 4.46 & 45.43 & 3.75 \\
\hline
\end{tabular}

TABLE 2. Effect of storage stability on chlorpyrifos $48 \%$ w/v EC of three different manufacture sources at room temperature for $1,2,4,6,8,10,12$ weeks.

\begin{tabular}{|c|c|c|c|c|c|c|}
\hline \multirow{2}{*}{$\begin{array}{c}\text { Storage } \\
\text { periods } \\
\text { (Weeks) }\end{array}$} & \begin{tabular}{c} 
Source I \\
\cline { 2 - 6 } \\
\cline { 2 - 7 } \\
conlorpyrifos \\
\%
\end{tabular} & \multicolumn{2}{c|}{ Source II } & \multicolumn{2}{c|}{ Source III } \\
\hline 0 & 47.02 & 0 & 47.09 & 0 & 47.2 & 0 \\
\hline 1 & 46.87 & 0.32 & 46.86 & 0.49 & 47.14 & 0.13 \\
\hline 2 & 46.78 & 0.51 & 46.76 & 0.70 & 46.77 & 0.91 \\
\hline 4 & 46.75 & 0.57 & 46.47 & 1.32 & 46.64 & 1.19 \\
\hline 6 & 46.68 & 0.72 & 46.27 & 1.74 & 46.59 & 1.29 \\
\hline 8 & 46.56 & 0.98 & 46.04 & 2.23 & 46.46 & 1.57 \\
\hline 10 & 46.18 & 1.79 & 45.93 & 2.46 & 46.44 & 1.61 \\
\hline 12 & 46.025 & 2.12 & 45.69 & 2.97 & 46.11 & 2.31 \\
\hline
\end{tabular}

TABLE 3. Effect of storage stability on chlorpyrifos $48 \%$ w/v EC of three different manufacture sources at $72 \pm 2{ }^{\circ} \mathrm{C}$ for $1,2,3,4,5$ days.

\begin{tabular}{|c|c|c|c|c|c|c|}
\hline \multirow{2}{*}{$\begin{array}{c}\text { Storage } \\
\text { periods } \\
\text { (Days) }\end{array}$} & $\begin{array}{c}\text { Shlorpyrifos } \\
\text { content (w/v) } \\
\%\end{array}$ & $\begin{array}{c}\text { Loss } \\
\%\end{array}$ & $\begin{array}{c}\text { Chlorpyrifos } \\
\text { content (w/v) } \\
\text { \% }\end{array}$ & $\begin{array}{c}\text { Loss } \\
\%\end{array}$ & $\begin{array}{c}\text { Chlorpyrifos } \\
\text { content (w/v) } \\
\text { \% }\end{array}$ & $\begin{array}{c}\text { Loss } \\
\%\end{array}$ \\
\hline 0 & 47.02 & 0 & 47.09 & 0 & 47.2 & 0 \\
\hline 1 & 45.74 & 2.72 & 45.22 & 3.97 & 45.52 & 3.56 \\
\hline 2 & 44.69 & 4.96 & 44.35 & 5.82 & 44.46 & 5.81 \\
\hline 3 & 44.01 & 6.4 & 43.89 & 6.79 & 43.52 & 7.79 \\
\hline 4 & 43.42 & 7.66 & 43.74 & 7.11 & 42.78 & 9.36 \\
\hline 5 & 41.79 & 11.12 & 41.30 & 12.30 & 41.35 & 12.39 \\
\hline
\end{tabular}




\section{Effect of storage stability on the formation of sulfotep}

The data from Table 4 showed the effect of storage at $54 \pm 2{ }^{\circ} \mathrm{C}$ for 1,3 , 7, 14, 21 days, and $72 \pm 2{ }^{\circ} \mathrm{C}$ for $1,2,3,4,5$ days on the formation of sulfotep. We found that the formation of sulfotep was not affected by storage at $54{ }^{\circ} \mathrm{C}$ and $72{ }^{\circ} \mathrm{C}$ and that for the three manufactured sources of chlorpyrifos I, II and III, and also sulfotep formation was not affected by storage at room temperature according to Table 5. Also, sulfotep found from source I and III was in allowed limits according to FAO specifications for chlorpyrifos (2008) where the maximum level of sulfotep in chlorpyrifos $48 \% \mathrm{EC}$ is $0.3 \%$ of chlorpyrifos content, but the results from source II the sulfotep found was more than the allowed limits according to FAO specifications and that was found before storage and after storage at $25^{\circ} \mathrm{C}$, $54 \pm 2{ }^{\circ} \mathrm{C}$ and $72 \pm 2{ }^{\circ} \mathrm{C}$. This may be attributed to the manufacturing process ${ }^{(13)}$, that sulfotep can be produced as byproduct from hydrolysis of diethyl thionyl phosphoryl chloride (DETC) ${ }^{(14)}$ according to the following equation:

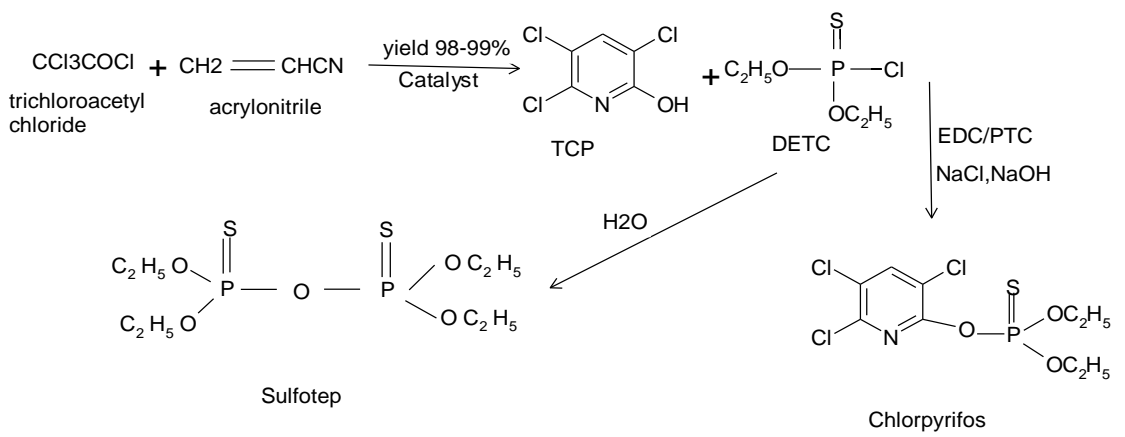

Also, these obtained results were in agreement with Allender \& James ${ }^{(5)}$ who reported that the sulfotep content of the commercial products did not show any correlation with storage time. 
The Quality of Chlorpyrifos Emulsifiable Concentrate Formulations

669

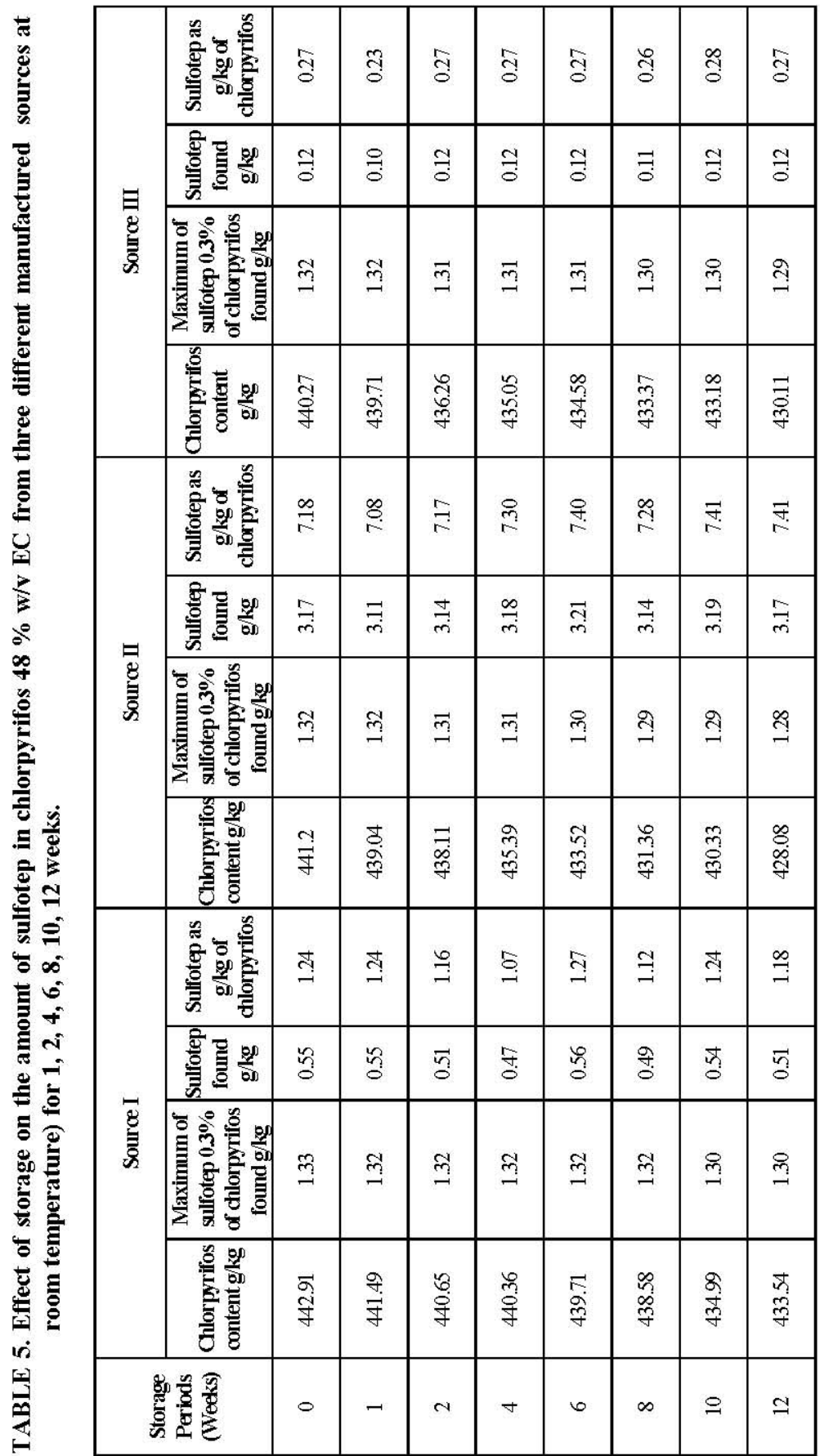

Egypt. J. Chem. 53, No. 5 (2010) 


\section{References}

1. Sultatos, L.G. and Murphy, S.D., Kinetic analyses of the microsomal biotransformation of the phosphorothioate insecticide chlorpyrifos and parathion. Fund. Appl. Toxicol. 3, 16-21 (1983).

2. Sultatos, L.G., Shao, M. and Murphy, S.D., The role of hepatic biotransformation in mediating the acute toxicity of the phosphorothionate insecticide chlorpyrifos. Toxicol. Appl. Phramacol. 73, 60-68 (1984).

3. The National Registration Authority (NRA), Review of Chlorpyrifos. Septmber, Volume 1 (2000).

4. Elbadry, B., Els. M. and Mohsin, A.H., Studies on comparative persistence of chlorpyrifos fenthion and pirimiphos-methyl in their formulated trade products under certain environmental conditions, determinations of their finger print and estimation of their impurities. Egypt J. Appl. Sci. 22(2A), 362-398 (2007).

5. Allender, W. J. and James K., Determination of chlorpyrifos and its major breakdown products in technical formulations. Bull. Environ. Contam. Toxicol. 46, 313-319 (1991).

6. Ambrus, A., Hamilton, D.J., Kuiper, H.A. and Racke, K.D., Significance of impurities in the safety evaluation of crop protection products. Pure Appl. Chem. 75, (7), 937-973 (2003).

7. Karr, J. J., Analysis of diazinon for impurities and degradation material. J. Assoc. off. Anal. Chem. 68, 929 - 934 (1985)..

8. Margot, A. and Gysin, H., Diazinon, its decomposition products and properties. Helv. Chim. Acta. 52, 1562-1573 (1957).

9. Collaborative International Pesticides Analytical Council, CIPAC Handbook $\underline{\mathbf{f}}$ MT 46 pp. 148-150 (1995) .

10. Smith, G.N., Ultraviolet light decomposition studies with dursban and 3,5,6trichloro-2-pyridinol. J. Econ. Entomol. 61, 793-799 (1968).

11. Walia, S., Dureja, P. and Mukerjee, S.K., New photodegradation products of chlorpyrifos and their detection on glass, soil, and leaf surfaces. Arch. Environ. Contam. Toxicol. 17, 183-188 (1988).

12. Jack R. Plimmer, "Handbook of Pesticide Toxicology" $2^{\text {nd }}$ edition, Academic Press. pp. 95-107 (2001).

13. Martinuzzi, E. A., Colonna, A. O. and Braz, P., Patent; Br 8703983 (1987).

14. Fakhraian, H., Moghimi, A., Ghadiri, H., Dehnavi, M.A. and Sadeghi, M. Reinvestigation of phase-transfer-catalyzed chlorpyrifos synthesis. Org. Proc. Res. Dev. 8(4), 680-684 (2004).

(Received 2/6/2010;

accepted 23/9/2010)

Egypt. J. Chem. 53, No. 5 (2010) 
مدى جودة مستحضرات الكلوربيريفوس القابلة للاستحلاب

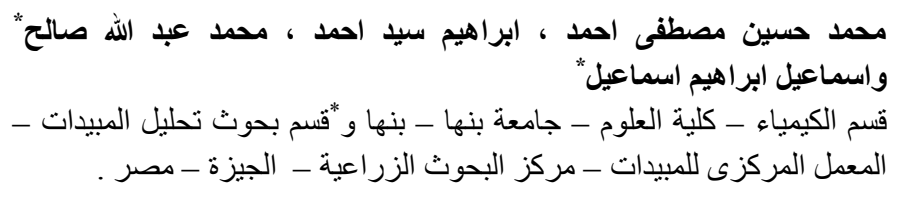

أجريت هذه الدراسة لبحث تكسير الكلوربيريفوس ومدى تكوين شائبته سلفوتب

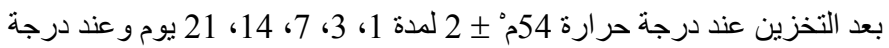

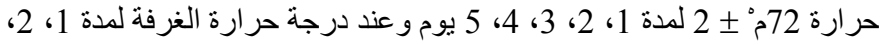

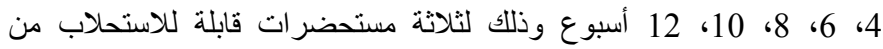

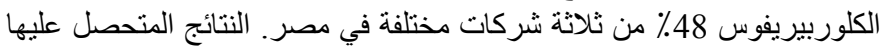

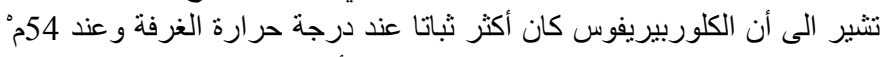

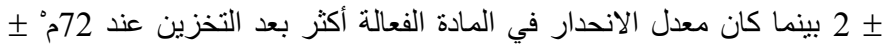

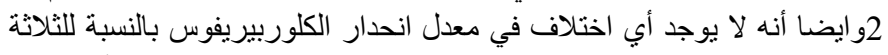

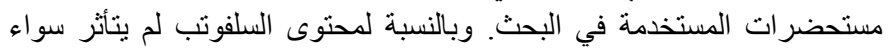

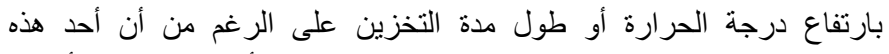

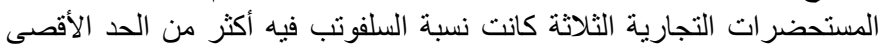
المسموح به بالنسبة لمواصفات منظمة الأغذية والزراعة المبلة للكلوربيريفوس (2008). 